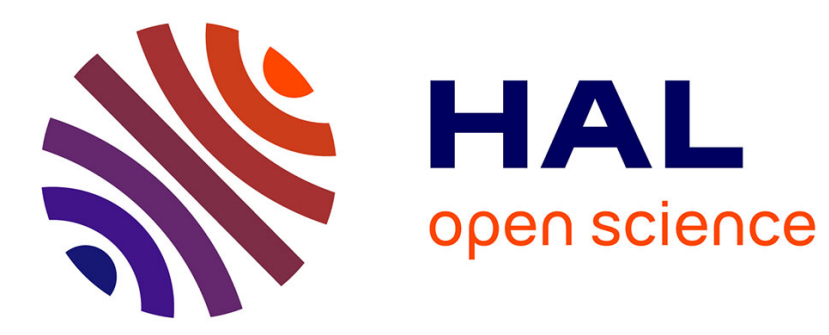

\title{
The Long Recurrence Intervals of Small Repeating Earthquakes May Be Due to the Slow Slip Rates of Small Fault Strands
}

J. Williams, J. Hawthorne, O. Lengliné

\section{- To cite this version:}

J. Williams, J. Hawthorne, O. Lengliné. The Long Recurrence Intervals of Small Repeating Earthquakes May Be Due to the Slow Slip Rates of Small Fault Strands. Geophysical Research Letters, 2019, 46 (22), pp.12823-12832. 10.1029/2019GL084778 . hal-03054321

\section{HAL Id: hal-03054321 \\ https://hal.science/hal-03054321}

Submitted on 18 Nov 2021

HAL is a multi-disciplinary open access archive for the deposit and dissemination of scientific research documents, whether they are published or not. The documents may come from teaching and research institutions in France or abroad, or from public or private research centers.
L'archive ouverte pluridisciplinaire HAL, est destinée au dépôt et à la diffusion de documents scientifiques de niveau recherche, publiés ou non, émanant des établissements d'enseignement et de recherche français ou étrangers, des laboratoires publics ou privés.

$$
\text { Copyright }
$$




\section{Geophysical Research Letters}

\author{
RESEARCH LETTER \\ 10.1029/2019GL084778 \\ Key Points: \\ - We explore why small repeating \\ earthquakes have surprisingly long \\ recurrence intervals \\ - Find that the scaling between \\ recurrence interval and moment \\ differs between closely and widely \\ spaced earthquake sequences \\ - Spacing-dependent recurrence \\ interval scaling could result \\ from spatially variable or fault \\ strand-dependent slip rates
}

Supporting Information: - Supporting Information S1 - Data Set S1

Correspondence to: J. R. Williams,

ee11j2w@leeds.ac.uk

Citation:

Williams, J. R., Hawthorne, J. C., \& Lengliné, O. (2019). The long recurrence intervals of small repeating earthquakes may be due to the slow slip rates of small fault strands. Geophysical Research Letters, 46, 12,823-12,832. https://doi.org/10. 1029/2019GL084778

Received 30 JUL 2019 Accepted 18 OCT 2019 Accepted article online 29 OCT 2019 Published online 19 NOV 2019

(C)2019. American Geophysical Union. All Rights Reserved.

\section{The Long Recurrence Intervals of Small Repeating Earthquakes May Be Due to the Slow Slip Rates of Small Fault Strands}

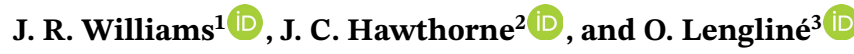 \\ ${ }^{1}$ School of Earth and Environment, University of Leeds, Leeds, UK, ${ }^{2}$ Department of Earth Sciences, University of \\ Oxford, Oxford, UK, ${ }^{3}$ École et Observatoire des Sciences de la Terre, Université de Strasbourg, Strasbourg, France
}

\begin{abstract}
Observations since 1998 have revealed that repeating earthquakes, and particularly small repeating earthquakes, occur less often than expected given their seismically derived slip and the regional fault slip rate. Here we test the hypothesis that small repeaters occur infrequently because they occur on fault segments or strands with low slip rates. We analyze the recurrence interval-moment scaling of earthquake sequences near Parkfield, California. We find that closely spaced sequences, which likely occur on the same fault strand and respond to the same slip rate, follow a $M_{0}^{\frac{1}{3}}$ scaling consistent with seismic slip rates while widely spaced sequences, which likely occur on different strands, follow a $M_{0}^{0.17}$ scaling consistent with the previous counterintuitive observations. These results suggest that spatially varying slip rates could create the $M_{0}^{0.17}$ recurrence interval scaling, though we cannot exclude other explanations.
\end{abstract}

Plain Language Summary We study repeating earthquakes, which repeatedly rupture part of a fault. Previous observations have shown that the cumulative slip in repeating earthquakes is smaller than the slip estimated from geological observations. This difference in slip means that the intervals between earthquakes are longer than expected, especially for smaller earthquakes. We examine whether the time between repeating earthquakes is long because small repeating earthquakes occur on a collection of shorter fault strands that exist within and contribute to the larger fault regime. We suggest that smaller earthquakes are more likely to occur on shorter fault strands and that shorter strands are likely to have lower slip rates than longer strands. Earthquake patches on shorter strands may be loaded slowly, so that the small earthquakes occur less often than expected. To test this possibility, we examine whether earthquakes that occur close together respond to the same slip rate. We find that closely spaced earthquakes do respond to the same slip rate, and widely spaced earthquakes respond to different slip rates. Our observations indicate that small repeating earthquakes may occur on short low slip rate fault strands.

\section{Introduction}

Repeating earthquakes are earthquakes that repeatedly rupture particular patches of faults (Nadeau \& Johnson, 1998; Uchida \& Bürgmann, 2019). They are recognized via their similar waveforms and consistent rupture area and are often used to track the slip rate of the creeping faults that host them (e.g., Igarashi et al., 2003; Materna et al., 2018; Meng et al., 2015; Nadeau \& Johnson, 1998; Nadeau \& McEvilly, 1999; Schmittbuhl et al., 2016; Uchida et al., 2016). Repeaters have been used to track slip rates on strike-slip faults (e.g., Lengliné \& Marsan, 2009; Nadeau \& Johnson, 1998; Peng \& Ben-Zion, 2005; Schaff et al., 1998; Schmittbuhl et al., 2016; Templeton et al., 2008), subduction zones (e.g., Dominguez et al., 2016; Hatakeyama et al., 2017; Igarashi et al., 2003; Yamashita et al., 2012; Ye et al., 2014; Yu, 2013; Zhang et al., 2008), thrust faults (e.g., Chen et al., 2008), and triple junctions (e.g., Chen \& McGuire, 2016; Materna et al., 2018), but the physics that controls repeaters' recurrence rates remains poorly understood.

If all of the slip on repeating earthquake patches accumulates in earthquakes, the cumulative earthquake slip should match the long-term fault slip rate and the slip per earthquake should equal the slip rate multiplied by the repeating earthquake's recurrence interval. However, observed repeating earthquakes occur less often than one would expect given long-term slip rates estimated from geodesy and geology (e.g., Chen et al., 2007; Lengliné \& Marsan, 2009; Nadeau \& Johnson, 1998; Nadeau et al., 2004). 


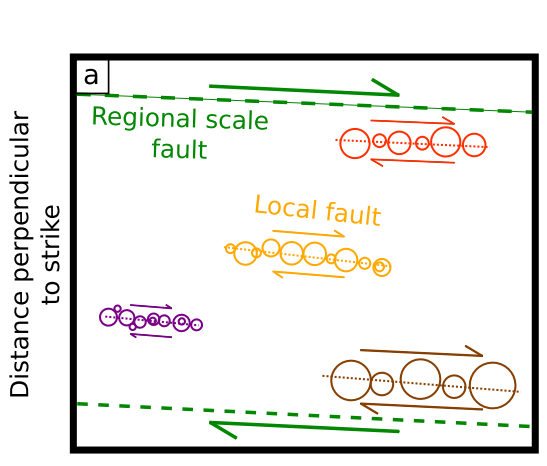

Distance along strike

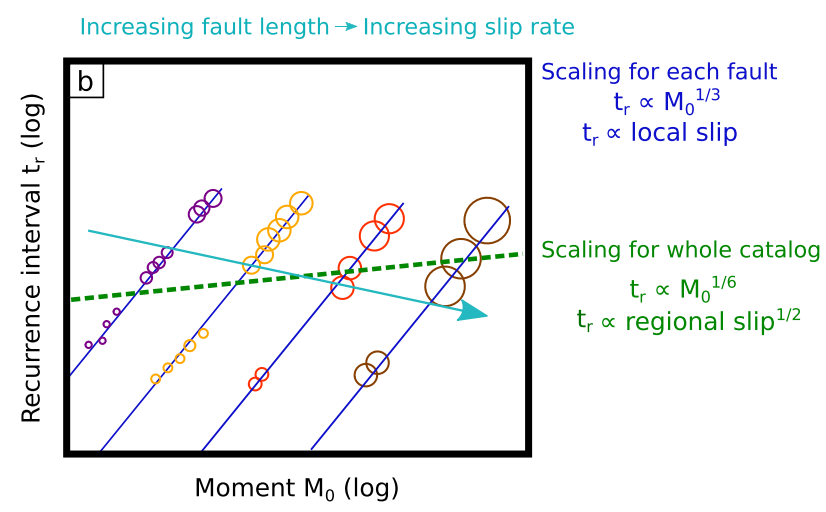

Figure 1. Conceptual model of our hypothesis. (a) Map view of earthquake sequences (circles) on different fault strands (dotted lines) within a regional scale fault (green dashed line). Larger fault strands have higher slip rates (larger arrows) and can host larger earthquakes (larger radii). (b) Hypothetical recurrence interval versus moment plots for earthquake sequences that could exist on each fault strand. The solid blue lines indicate a $M_{0}^{\frac{1}{3}}$ scaling of recurrence intervals on each fault strand, while the dashed green line illustrates a $M_{0}^{0.17}$ scaling that might be observed by considering all the earthquakes together.

This slip or recurrence interval discrepancy is especially large for small repeating earthquakes. Observed repeater recurrence intervals $t_{r}$ scale with moment $M_{0}$ as $M_{0}^{0.17}$ (Chen et al., 2007; Lengliné \& Marsan, 2009; Nadeau \& Johnson, 1998; Nadeau et al., 2004) but if earthquakes are assumed to have magnitude-independent stress drops (e.g., Allmann \& Shearer, 2007, 2009; Shearer et al., 2006), the slip per earthquake should scale as $M_{0}^{\frac{1}{3}}$. And if earthquakes accommodate all the slip on a given patch, the recurrence interval is equal to the slip per earthquake divided by the long-term slip rate. The predicted $t_{r}$ thus scales as $M_{0}^{\frac{1}{3}}$ (Beeler et al., 2001; Nadeau \& Johnson, 1998; see supporting information for full derivation) and decreases more quickly with decreasing moment than the observed $t_{r}$.

Nadeau and Johnson (1998) were the first to identify the $M_{0}^{0.17}$ recurrence interval-moment scaling. They and later authors suggested that smaller repeating earthquakes could have higher or more heterogeneous stress drops (e.g., Dreger et al., 2007; Kim et al., 2016; Nadeau et al., 2004). However, stress drops of these earthquakes are observed to be independent of magnitude (e.g., Allmann \& Shearer, 2007) and much lower than Nadeau and Johnson (1998) suggested (e.g., Abercrombie, 2014; Imanishi et al., 2004).

The correct physical model for repeaters remains unclear, and a range of models have been proposed. Repeating earthquakes could have long recurrence intervals because some of the slip on repeating earthquake patches accumulates aseismically or via partial ruptures in postseismic, interseismic, or preseismic periods (Beeler et al., 2001; Chen \& Lapusta, 2009, 2019; Cattania \& Segall, 2019). Alternatively, repeating earthquakes could have long recurrence intervals because they occur within regions of low slip rate or low stressing rate. Earthquakes could occur in the rupture area of larger earthquakes (Anooshehpoor \& Brune, 2001), on the border of a larger locked asperity (Sammis \& Rice, 2001), or within a cluster of asperities (Johnson \& Nadeau, 2002).

Here we seek to test the latter models: to assess whether spatially variable slip rates could create the long recurrence intervals of repeating earthquakes. We also suggest another potential origin for spatially variable slip rates: Earthquakes could occur on an array of fault strands of various lengths which together constitute the main fault. The slip rate on each strand is smaller than the regional slip rate, as the regional rate is a sum of all the strands' slip rates. The slip on these strands is affected by complex geometry and interaction between faults, but geological observations and modeling imply that the slip accumulated on given fault strands scales linearly with the strand's length (e.g., Carvell et al., 2014; Cowie \& Scholz, 1992; Scholz et al., 1993; Torabi \& Berg, 2011; Walsh \& Watterson, 1988; Watterson, 1986). If all fault strands form at the same time, the shorter fault strands should have lower slip rates than the longer fault strands.

We may thus hypothesise that small earthquakes have especially long recurrence intervals because they are small enough to occur on short fault strands, which have low slip rates. There may be no discrepancy in slip on a local scale, and slip may scale as $M_{0}^{\frac{1}{3}}$ on each fault strand (blue lines in Figure 1b). We may infer a 


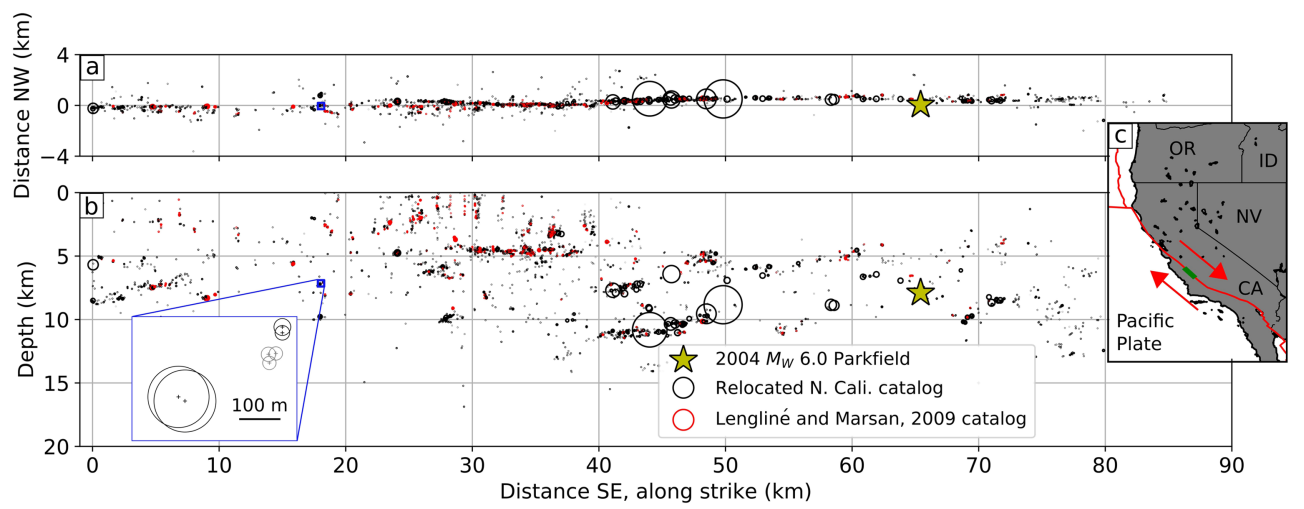

Figure 2. (a) NCSN earthquake locations in map view along the Parkfield segment of the San Andreas Fault. Earthquakes after the day before the $2004 M_{\mathrm{W}} 6$ earthquake are excluded. Earthquakes that appear in the catalog of Lengliné and Marsan (2009) are marked in red. The hypocenter of the $2004 M_{\mathrm{W}} 6$ earthquake is marked by the yellow star. (b) Earthquake locations along strike versus depth. The inset plot demonstrates two examples of two-earthquake sequences (black circles) that we find using our approach. The third obvious cluster of earthquakes did not meet our criteria (gray circles). The radii of these earthquakes is calculated in the text. (c) Larger-scale view of study area (green) in global context.

slip deficit on a regional scale only because we compare the repeating earthquake rate with the regional slip rate, which is the sum of the slip rates on the collection of fault strands (green dashed line in Figure 1b).

Here we test the hypothesis that fault strand- or segment-dependent slip rates create repeating earthquakes' $M_{0}^{0.17}$ recurrence interval scaling. We note that if spatially variable slip rates create the $M_{0}^{0.17}$ scaling, that scaling should be apparent among widely spaced earthquake sequences. But closely spaced sequences should respond to the same local slip rate and thus have a scaling closer to $M_{0}^{\frac{1}{3}}$. So we compare the recurrence intervals of closely and widely spaced earthquake sequences near Parkfield, California.

\section{Data: Repeating Earthquake Sequences}

We search for distance-dependent scaling using two data sets from Parkfield, California.

\subsection{Earthquake Sequences Identified by Lengliné and Marsan (2009)}

We analyze a catalog of repeating earthquake sequences identified by Lengliné and Marsan (2009). The catalog includes 334 repeating earthquake sequences composed of 2,414 M 0.94-3.19 earthquakes that occurred between 1984 and 2007. Lengliné and Marsan (2009) formed these sequences by requiring repeating earthquakes to have similar waveforms, $70 \%$ horizontal source overlap, and a magnitude difference of less than or equal to 0.2 magnitude units compared to any of the earthquakes in the sequence. Many of these sequences were perturbed by the $2004 M_{\mathrm{W}} 6.0$ Parkfield earthquake, however, so we truncate the catalog 1 day before the 2004 event and thus analyze 220 sequences composed of 1,540 earthquakes (Figure 2). We assume that the earthquake rate is stable in the 1984-2004 time interval.

\subsection{Two-Earthquake Sequences from the Relocated NCSN Catalog}

We also identify pairs of colocated earthquakes, which we think of as two-earthquake sequences, directly from the Northern California Seismic Network (NCSN) earthquake catalog, as relocated by Waldhauser and Schaff (2008) and Waldhauser (2009). We select a subset of this catalog in the 90-km-long area shown in Figure 2 (coordinates in supporting information Table S1) and exclude any earthquakes with depths shallower than $4 \mathrm{~km}$ as their depth resolution is poorer (Figure 2). We analyze earthquakes between 1984 and 2004, again stopping 1 day before the 2004 Parkfield event. The analyzed relocated catalog consists of 5,255 events with magnitudes of $M 0.15-4.9$.

To begin, we calculate the earthquakes' moments $M_{0}$ from their catalog magnitudes, assuming $M_{0}=$ $10^{1.6 M+9.05} \mathrm{Nm}$ (Wyss et al., 2004). We use the moment to estimate earthquake rupture radius $R$, assuming an elliptical slip distribution (Eshelby, 1957) and a stress drop $\Delta \sigma$ of $10 \mathrm{MPa}$, as has been inferred for the Parkfield area (e.g., Abercrombie, 2014; Allmann \& Shearer, 2007; Imanishi et al., 2004): 


$$
R=\left(\frac{7}{16} \frac{M_{0}}{\Delta \sigma}\right)^{\frac{1}{3}}
$$

Next, we use a crude approach to identify two-earthquake sequences of repeating earthquakes - earthquakes that rupture the same area-without using waveform correlation. For each earthquake in the catalog, we search for the next earthquake in time that is located within one radius horizontally and vertically, and which has a magnitude within 0.3 magnitude units. We allow a 34-m uncertainty on the horizontal location and an 80-m uncertainty on the vertical location. These uncertainties are the $95 \%$ confidence limits for relative location errors in the relocated catalog (Waldhauser, 2009, catalog version 201112.1). We require that one earthquake in each two-earthquake sequence has a magnitude greater than $M 1.3$, to avoid having sequences with missing events. Earthquakes with $M<1.1$ may be missing from the catalog, as a frequency-magnitude plot suggests a Gutenberg-Richter distribution with a roll-off at magnitudes below 1.1 (Figure S1).

This search for similar earthquakes identifies 1,230 two-earthquake sequences. Note that our analysis of these sequences assumes that all of these colocated events are repeating earthquakes. This assumption seems acceptable for the Parkfield region; up to 55\% of small earthquakes in smaller-scale studies of this region have been identified as repeating earthquakes using waveform correlation analysis (Nadeau et al., 2004), and we exclude isolated events with our relative location requirements.

\section{Method and Results}

\subsection{Analyzing Earthquake Sequences in the Lengliné and Marsan Catalog}

We begin by analyzing the median recurrence intervals and moments of each sequence in Lengliné and Marsan's (2009) catalog (gray dots in Figure 3a). The moment is calculated from the NCSN magnitudes using the calibration of Wyss et al. (2004), as described above. We also compute and plot the median recurrence intervals and moments in various moment bins (black squares). We compute 95\% confidence limits on the median recurrence intervals by jackknifing the sequence catalog. In each of 1,000 realizations, we remove $20 \%$ of the sequences and recompute the median recurrence interval and moment for each moment bin. The error bars in Figure 3a indicate 95\% confidence limits derived from these realizations.

We use these uncertainty estimates when we estimate the best fitting recurrence interval-moment slope, or scaling exponent $\beta$. When fitting $\beta$, we weight each point by 1 divided by the variance implied by the $95 \%$ confidence limits on each point. We then jackknife again to estimate uncertainties on the scaling exponent. We recalculate the best fitting exponent 1,000 times, excluding $20 \%$ of the earthquake catalog each time. The slope of the relation between these median recurrence intervals and moment bins in log-log space is equal to the scaling exponent $\beta$ of the recurrence interval-moment relation discussed earlier $\left(t_{r} \propto M_{0}^{\beta}\right)$. The slope $\beta$ should be equal to $\frac{1}{3}$ if all earthquakes have the same stress drop and the slip per earthquake is equal to the regional slip rate multiplied by the recurrence interval. Given the limited number of sequences in Lengliné and Marsan's (2009) catalog, the recurrence interval-moment scaling exponent is poorly constrained at 0.15 (95\% confidence limits of 0.13 and 0.20 ) but is consistent with the shallower $\beta=\frac{1}{6}$ scaling, which is equivalent to the $\beta=0.17$ scaling identified by Nadeau and Johnson (1998).

We want to know if the recurrence interval-moment scaling is different for closely and widely spaced earthquake sequences. As noted in section 1, if closely spaced earthquake sequences are sensitive to similar slip rates, recurrence intervals may locally scale as $M_{0}^{\frac{1}{3}}$ even though widely spaced sequences show a $M_{0}^{0.17}$ scaling, on average. So we consider pairs of earthquake sequences. For each pair, we calculate the ratio of the sequences' median recurrence intervals and the ratio of the sequences' median moments. All the ratios are plotted in Figure 4a (gray dots). Next, we bin and examine the ratios' scaling by intersequence distance. We compute the inter-sequence distance by computing the distance between the median locations of each earthquake sequence. For each distance bin, we compute the median recurrence interval ratios and median moment ratios for various moment ratio bins (colored symbols with error bars). Finally, we estimate the recurrence interval-moment scaling for each distance bin by fitting lines in log-log space through the median recurrence interval ratios.

We compute $95 \%$ confidence limits on the median recurrence interval ratios by jackknifing the sequence catalog as above. The error bars in Figure 4a indicate 95\% confidence limits derived from the 1,000 realizations of the jackknifed catalog. We use these uncertainty estimates when we estimate the best fitting slopes, 

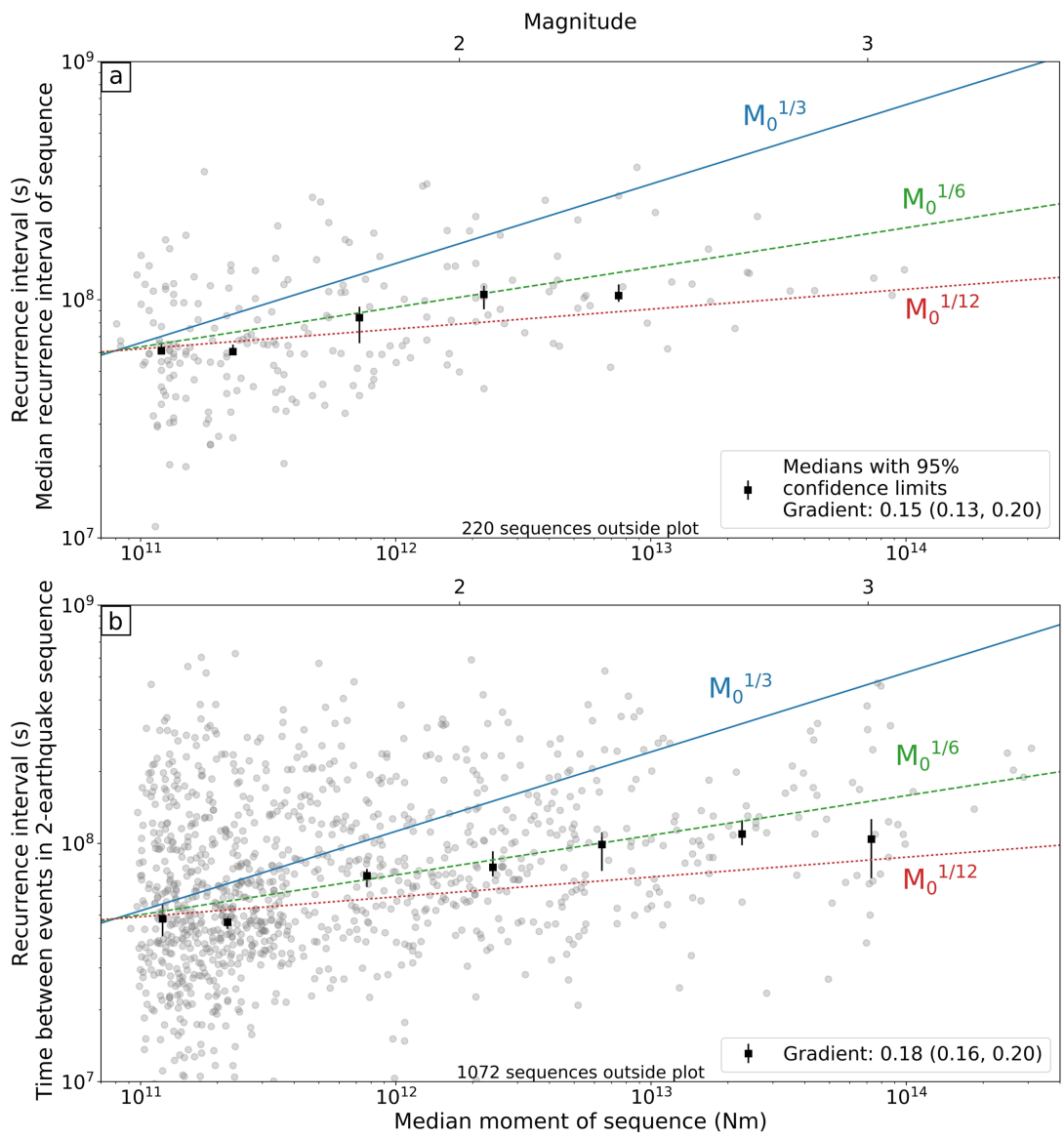

Figure 3. Median recurrence interval versus median moment for sequences from (a) the repeating earthquakes catalog of Lengliné and Marsan (2009) and (b) the relocated Northern California catalog (Waldhauser \& Schaff, 2008;

Waldhauser, 2009) on a log-log scale. Individual values are plotted as gray circles, with medians for moment bins shown as black squares. The error bars on the medians indicate $95 \%$ confidence limits, which were estimated via jackknifing (details in the text). The $t_{r}$ scaling relations of $M_{0}^{\frac{1}{3}}, M_{0}^{\frac{1}{6}}\left(M_{0}^{0.17}\right)$, and $M_{0}^{\frac{1}{12}}$ are plotted as solid blue, dashed green, and dotted red lines, respectively. Some data are outside the range plotted here as detailed in the annotations on each plot.

or scaling exponent $\beta$, for the median recurrence interval ratios and moment ratios for each distance bin, using the same approach as the simpler recurrence interval-moment slope calculation.

To ensure high-quality statistics, we prefer to only consider medians in distance and moment bins that include at least 20 sequences with at least 10 sequences that figure in the moment ratios' numerators and at least 10 sequences that figure in the moment ratios' denominators. We plot medians that do not fulfil these requirements with open symbols and dashed error bars, and where possible we do not use them in our exponent calculation. Lengliné and Marsan's (2009) catalog includes a limited number of sequences, however, and none of the distance bins of interest meet this 20 -sequence requirement. For completeness, we nevertheless compute scaling exponents for these distance bins using the available (poorly constrained) medians and plot them with open symbols in the inset panel in Figure 4a. All of the confidence intervals on these scaling exponents include 0.17 and exclude $\frac{1}{3}$, but the confidence interval width is likely underestimated due to the low number of sequences used in the jackknifing.

\subsection{Analyzing Two-Earthquake Sequences in the Relocated NCSN Catalog}

We perform a similar analysis for the two-earthquake sequences identified in the NCSN catalog. We first calculate the time between the earthquakes in each sequence - the recurrence interval — and plot it against the sequence's average moment (Figure 3b). We then estimate the scaling exponent of the calculated recurrence intervals with moment using the same approach as above. The scaling exponent of these calculated 

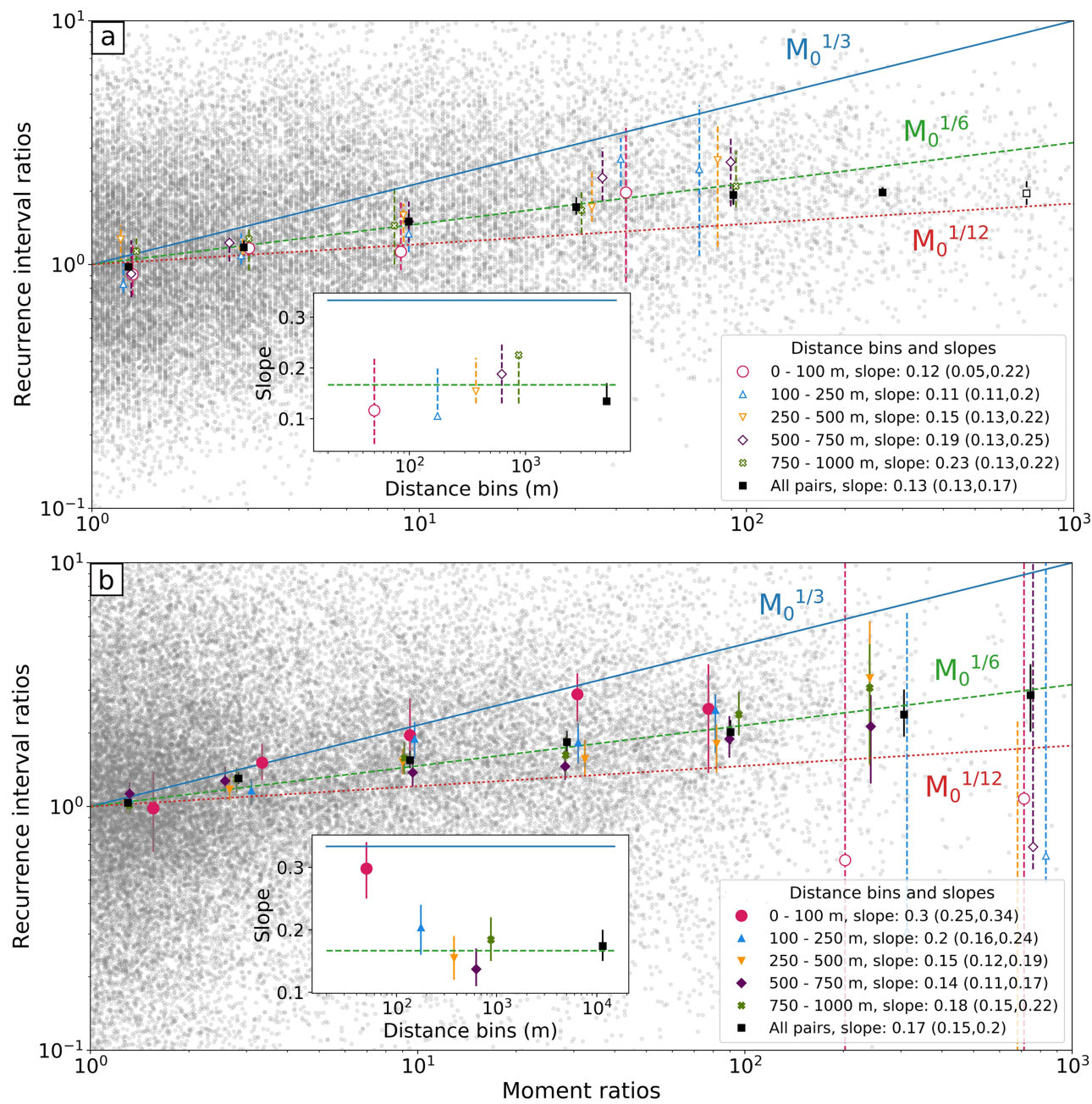

Figure 4. Recurrence interval ratios versus moment ratios (small gray circles) for pairs of sequences in (a) the catalog of Lengliné and Marsan (2009) and (b) the relocated NCSN catalog (Waldhauser \& Schaff, 2008; Waldhauser, 2009).

The medians of sequences in different moment ratio and distance bins are plotted with varying colors and symbols, as described in the legend. Open symbols with dashed error bars are bins which did not contain at least 10 unique pairs in the numerator and denominator of the ratios. Those points are excluded from the slope calculation. Inset plots: slopes for various distance bins. Slopes with open symbols have been calculated using only points with open symbols, so they have large uncertainties that are not captured by the $95 \%$ confidence limits. Recurrence interval scaling relations are as in Figure 3. Error bars representing 95\% confidence limits are calculated using jackknifing as described in the text.

recurrence intervals with moment is 0.18 (95\% confidence limits of 0.16 and 0.20$)$, similar to the $M_{0}^{0.17}$ scaling of recurrence intervals of repeating earthquakes obtained from waveform correlation by Nadeau and Johnson (1998).

We again want to compare each earthquake sequence with closely and widely spaced sequences, so we compute recurrence interval and moment ratios for all possible sequence pairs. We estimate the distance between these sequences as the distance between the locations of the first events in the two-earthquake sequences. We have experimented with different approaches for estimating the distance between sequences and find no significant impact on our results (Figures S21 and S22). We do not want to compare two-earthquake sequences that are part of the same longer sequence, however, so we exclude ratios of sequences that are within $200 \mathrm{~m}$ and 0.3 magnitude units of each other. Then we compute median recurrence interval and moment ratios for a range of moment ratio and distance bins and calculate $95 \%$ confidence intervals (error bars) and the best fitting scaling exponent using jackknifing, following the same procedure as for Lengliné and Marsan's (2009) catalog. In each of 1,000 jackknifed realizations, we remove $20 \%$ of the earthquake catalog, exclude any two-earthquake sequences that have lost an earthquake, and recompute recurrence interval ratios, moment ratios, and scaling exponents. 
We next fit lines to the median recurrence interval ratios and moment ratios to obtain scaling exponents for each distance bin. The scaling exponents obtained for earthquakes separated by more than $100 \mathrm{~m}$ are scattered around 0.17 and include 0.17 in their $95 \%$ confidence intervals (Figure $4 \mathrm{~b}$ ). The 0 - to 100 -m distance bin is an exception, however. It has a best fitting scaling exponent of 0.3 and includes $\frac{1}{3}$ within its uncertainty intervals.

\subsection{Testing for Bias in Our Analysis}

We repeat our analysis with a range of modifications to check that our observed recurrence interval-moment scaling is not biased by our approach. Full details and discussion are available in the supporting information. We test whether our result changes if we modify the bin widths (Figure S17), the averaging method (Figure S18), the time period analyzed (Figures S5, S11, and S12), the earthquake location uncertainty (Figure S13), or the stress drop assumed to estimate earthquake radii (Figures S7 and S8), or if we do not simply create pairs but attempt to track sequences from the NCSN locations (Figure S9). In these tests, the exponent for the 0 - to 100-m distance bin remains elevated, albeit not quite as elevated. It has best fitting values between 0.23 and 0.3 , and according to the jackknife probabilities, it has a 75-95\% chance of exceeding the average exponent of the other distance bins. We also find that our crude approach identifies $65 \%$ of the repeating earthquakes in the catalog of Lengliné and Marsan (2009) within our region of interest (Figure S4), which suggests that our crude approach does a reasonable job of identifying repeating earthquakes.

\subsection{Validation With Synthetic Earthquake Catalogs}

To check that our code and methodology are appropriate, we analyze several synthetic catalogs. First, we consider a synthetic catalog where repeating earthquakes have recurrence intervals that scale as $M_{0}^{0.17}$. Our analysis recovers this $M_{0}^{0.17}$ scaling. Uncertainty-induced scatter in the scaling exponent is evenly distributed above and below 0.17 in all distance bins (Figure S23). We also analyze a catalog of earthquakes on multiple fault strands, where recurrence interval scales as $M_{0}^{\frac{1}{3}}$ on each fault strand and where each strand's slip rate scales as its length. This catalog simulates the scenario suggested in Figure 1. As expected, we retrieve a scaling exponent of close to $\frac{1}{3}$ for the lower distance bin and a reduced exponent of close to 0.17 for the wider distance bins in these catalogs (Figure S24).

\section{Discussion}

We analyzed the recurrence interval-moment scaling of repeating earthquakes in two earthquake catalogs. The scaling exponents obtained by analyzing Lengliné and Marsan's (2009) sequences catalog appear to be inconsistent with spatially dependent slip rates, as the scaling exponents are scattered around 0.17 and do not vary with the distance between repeating earthquake sequences. As we note above, however, this catalog usually has less than 10 unique sequences in the numerator and denominator of each moment ratio and distance bin and therefore a large uncertainty on the scaling exponents which is not necessarily captured in our jackknifing.

The scaling exponents obtained from two-earthquake sequences in the NCSN catalog are better resolved, and they are consistent with spatially dependent slip rates. The two-earthquake sequences within $100 \mathrm{~m}$ of each other give a high scaling exponent with a best fitting value of 0.3 obtained from 1,878 pairs of sequences. This exponent's $95 \%$ confidence intervals of $0.25-0.34$ include $\frac{1}{3}$, the value expected when constant-stress drop repeaters occur in response to a locally uniform slip rate, without allowing for aseismic slip. The two-earthquake sequences which are 100-250 m apart also give an elevated exponent of 0.2 , with $95 \%$ confidence limits of $0.16-0.24$. More widely spaced sequences give scaling exponents close to the 0.17 value identified previously (e.g., Chen et al., 2007; Nadeau \& Johnson, 1998; Nadeau et al., 2004). The change in scaling could indicate that the background slip rate changes with location and that smaller earthquakes occur on regions of the fault with lower slip rate or lower stressing rate (Anooshehpoor \& Brune, 2001; Johnson \& Nadeau, 2002).

Our jackknife-based uncertainties suggest a distance-dependent change in scaling exponent with greater than $99 \%$ probability. However, these uncertainties may not include all sources of error, and in some of our tests for biases on the NCSN catalog, we found that the 0- to 100-m scaling exponent could be close to 0.17 within uncertainty. For example, we found a scaling exponent of $0.23(0.16-0.32)$ when we attempted to track longer sequences from the NCSN locations (Figure S9). Nevertheless, we note that in all of our tests on the NCSN catalog, the 0- to 100-m distance bin had the largest exponent (Figures S5-S22). 
The change in scaling at distances of $0-200 \mathrm{~m}$ is consistent with our use of primarily $M$ 1-2.5 earthquakes, which have diameters around 10-100 m. Such earthquakes could frequently occur on fault strands with lengths of $100 \mathrm{~m}$ or less. It may be that when we compare earthquake sequences within $200 \mathrm{~m}$ of each other, we are usually comparing sequences on the same fault, but when we compare earthquakes more than $200 \mathrm{~m}$ apart, we are usually comparing sequences on different faults (e.g., Waldhauser et al., 2004), which could have different slip rates.

Our results suggest that spatially dependent slip rates are a viable explanation of the scaling of repeating earthquakes' recurrence intervals with moment. This explanation would imply that the scaling first identified by Nadeau and Johnson (1998) reflects the properties of the fault system, not the properties of the earthquakes themselves. The results may indicate that we can further probe the fault system and learn about its fault strands and slip rates by examining the timing and spacing of repeating and non-repeating earthquakes.

Our results should be interpreted with caution, however. We analyze only one region here, and we use a crude approach to identify repeating earthquakes. There remain several other viable explanations for the recurrence interval scaling. The scaling could result from significant aseismic slip (Anooshehpoor \& Brune, 2001; Beeler et al., 2001; Chen \& Lapusta, 2009; Sammis \& Rice, 2001), partial ruptures of repeater patches (Cattania \& Segall, 2019; Chen \& Lapusta, 2019), or highly heterogeneous stress drops (Nadeau \& Johnson, 1998).

\section{Conclusions}

With this work, we sought to test the hypothesis that small repeating earthquakes have exceptionally long recurrence intervals because they occur preferentially on fault strands or segments with low slip rates. We examined the recurrence interval-moment scaling of repeating earthquakes in the Parkfield area using Lengliné and Marsan's (2009) repeating earthquake catalog and crudely identified sequences in the relocated NCSN catalog (Waldhauser \& Schaff, 2008; Waldhauser, 2009). With Lengliné and Marsan's (2009) catalog, we obtain a scaling within error of the $M_{0}^{0.17}$ scaling identified by Nadeau and Johnson (1998) for all subsets of the sequences. But with the NCSN location-based sequences, which have better spatial resolution, we recover that scaling only when we consider sequences that are more than $100 \mathrm{~m}$ apart. Sequences within $100 \mathrm{~m}$ of each other show a scaling close to $M_{0}^{\frac{1}{3}}$, as would be expected if the earthquakes have magnitude-independent stress drops and keep up with the local fault slip rates. This "normal" local scaling suggests that the $M_{0}^{0.17}$ scaling, which implies that smaller repeating earthquakes do not match the regional slip rate, can be explained by spatially varying slip rates or by a collection of fault strands that have size-dependent slip rates.

Acknowledgments

The Northern California Seismic Network earthquake catalog was accessed through the Northern California Earthquake Data Center (NCEDC; https://doi.org/10.7932/ NCEDC). Most of the NCSN earthquakes were relocated by Waldhauser and Schaff (2008) and Waldhauser (2009). The catalog of Lengliné and Marsan (2009) was provided by Olivier Lengliné (personal communication, August 31st 2018).

The two-earthquake sequence catalog we identified can be obtained from the University of Leeds repository (https:// doi.org/10.5518/727). Data processing was performed using Python. We would like to thank the Editor Gavin Hayes and two anonymous reviewers for their comments and suggestions which improved this manuscript. Joshua Williams was funded by a studentship from the National Environment Research Council SPHERES Doctoral Training Partnership (NE/L002574/1).

\section{References}

Abercrombie, R. E. (2014). Stress drops of repeating earthquakes on the San Andreas fault at Parkfield. Geophysical Research Letters, 41, 8784-8791. https://doi.org/10.1002/2014GL062079

Allmann, B. P., \& Shearer, P. M. (2007). Spatial and temporal stress drop variations in small earthquakes near Parkfield, California. Journal of Geophysical Research, 112, B04305. https://doi.org/10.1029/2006JB004395

Allmann, B. P., \& Shearer, P. M. (2009). Global variations of stress drop for moderate to large earthquakes. Journal of Geophysical Research, 114, B01310. https://doi.org/10.1029/2008JB005821

Anooshehpoor, A., \& Brune, J. N. (2001). Quasi-static slip-rate shielding by locked and creeping zones as an explanation for small repeating earthquakes at Parkfield. Bulletin of the Seismological Society of America, 91(2), 401-403. https://doi.org/10.1785/0120000105

Beeler, N., Lockner, D., \& Hickman, S. (2001). A simple stick-slip and creep-slip model for repeating earthquakes and its implication for microearthquakes at Parkfield. Bulletin of the Seismological Society of America, 91(6), 1797-1804. https://doi.org/10.1785/0120000096

Carvell, J., Blenkinsop, T., Clarke, G., \& Tonelli, M. (2014). Scaling, kinematics and evolution of a polymodal fault system: Hail Creek Mine, NE Australia. Tectonophysics, 632(C), 138-150. https://doi.org/10.1016/j.tecto.2014.06.003

Cattania, C., \& Segall, P. (2019). Crack models of repeating earthquakes predict observed moment-recurrence scaling. Journal of Geophysical Research: Solid Earth, 124, 476-503. https://doi.org/10.1029/2018JB016056

Chen, T., \& Lapusta, N. (2009). Scaling of small repeating earthquakes explained by interaction of seismic and aseismic slip in a rate and state fault model. Journal of Geophysical Research, 114, B01311. https://doi.org/10.1029/2008JB005749

Chen, T., \& Lapusta, N. (2019). On behaviour and scaling of small repeating earthquakes in rate and state fault models. Geophysical Journal International, 218(3), 2001-2018.

Chen, X., \& McGuire, J. J. (2016). Measuring earthquake source parameters in the Mendocino triple junction region using a dense OBS array: Implications for fault strength variations. Earth and Planetary Science Letters, 453, 276-287. https://doi.org/10.1016/j.epsl.2016. 08.022 
Chen, K. H., Nadeau, R. M., \& Rau, R.-J. (2007). Towards a universal rule on the recurrence interval scaling of repeating earthquakes? Geophysical Research Letters, 34, L16308. https://doi.org/10.1029/2007GL030554

Chen, K. H., Nadeau, R. M., \& Rau, R.-J. (2008). Characteristic repeating earthquakes in an arc-continent collision boundary zone: The Chihshang fault of eastern Taiwan. Earth and Planetary Science Letters, 276(3-4), 262-272. https://doi.org/10.1016/j.epsl.2008.09.021

Cowie, P. A., \& Scholz, C. H. (1992). Displacement-length scaling relationship for faults: Data synthesis and discussion. Journal of Structural Geology, 404(10), 1149-1156. https://doi.org/10.1016/0191-8141(92)90066-6

Dominguez, L. A., Taira, T., \& Santoyo, M. A. (2016). Spatiotemporal variations of characteristic repeating earthquake sequences along the Middle America Trench in Mexico. Journal of Geophysical Research: Solid Earth, 121, 8855-8870. https://doi.org/10.1002/2016JB013242

Dreger, D., Nadeau, R. M., \& Chung, A. (2007). Repeating earthquake finite source models: Strong asperities revealed on the San Andreas Fault. Geophysical Research Letters, 34, L23302. https://doi.org/10.1029/2007GL031353

Eshelby, J. D. (1957). The determination of the elastic field of an ellipsoidal inclusion, and related problems. Proceedings of the Royal Society of London A: Mathematical, Physical and Engineering Sciences, 241, 376-396. https://doi.org/10.1098/rspa.1957.0133

Hatakeyama, N., Uchida, N., Matsuzawa, T., \& Nakamura, W. (2017). Emergence and disappearance of interplate repeating earthquakes following the 2011 M9. 0 Tohoku-oki earthquake: Slip behavior transition between seismic and aseismic depending on the loading rate. Journal of Geophysical Research: Solid Earth, 122, 5160-5180. https://doi.org/10.1002/2016JB013914

Igarashi, T., Matsuzawa, T., \& Hasegawa, A. (2003). Repeating earthquakes and interplate aseismic slip in the northeastern Japan subduction zone. Journal of Geophysical Research, 108(B5), 2249. https://doi.org/10.1029/2002JB001920

Imanishi, K., Ellsworth, W. L., \& Prejean, S. G. (2004). Earthquake source parameters determined by the SAFOD Pilot Hole seismic array. Geophysical Research Letters, 31, L12S09. https://doi.org/10.1029/2004GL019420

Johnson, L. R., \& Nadeau, R. M. (2002). Asperity model of an earthquake: Static problem. Bulletin of the Seismological Society of America, 92(2), 672-686. https://doi.org/10.1785/0120000282

Kim, A., Dreger, D. S., Taira, T., \& Nadeau, R. M. (2016). Changes in repeating earthquake slip behavior following the 2004 Parkfield main shock from waveform empirical Green's functions finite-source inversion. Journal of Geophysical Research: Solid Earth, 121, 1910-1926. https://doi.org/10.1002/2015JB012562

Lengliné, O., \& Marsan, D. (2009). Inferring the coseismic and postseismic stress changes caused by the $2004 M_{w}=6$ Parkfield earthquake from variations of recurrence times of microearthquakes. Journal of Geophysical Research, 114, B10303. https://doi.org/10.1029/ 2008JB006118

Materna, K., Taira, T., \& Bürgmann, R. (2018). Aseismic transform fault slip at the Mendocino Triple Junction from characteristically repeating earthquakes. Geophysical Research Letters, 45, 699-707. https://doi.org/10.1002/2017GL075899

Meng, L., Huang, H., Bürgmann, R., Ampuero, J. P., \& Strader, A. (2015). Dual megathrust slip behaviors of the 2014 Iquique earthquake sequence. Earth and Planetary Science Letters, 411, 177-187. https://doi.org/10.1016/j.epsl.2014.11.041

Nadeau, R. M., \& Johnson, L. R. (1998). Seismological studies at Parkfield VI: Moment release rates and estimates of source parameters for small repeating earthquakes. Bulletin of the Seismological Society of America, 88(3), 790-814.

Nadeau, R. M., \& McEvilly, T. V. (1999). Fault slip rates at depth from recurrence intervals of repeating microearthquakes. Science, 285(5428), 718-721. https://doi.org/10.1126/science.285.5428.718

Nadeau, R. M., Michelini, A., Uhrhammer, R. A., Dolenc, D., \& McEvilly, T. V. (2004). Detailed kinematics, structure and recurrence of micro-seismicity in the SAFOD target region. Geophysical Research Letters, 31, L12S08. https://doi.org/10.1029/2003GL019409

Peng, Z., \& Ben-Zion, Y. (2005). Spatiotemporal variations of crustal anisotropy from similar events in aftershocks of the $1999 M 7.4$ Izmit and M 7.1 Düzce, Turkey, earthquake sequences. Geophysical Journal International, 160(3), 1027-1043. https://doi.org/10.1111/j. 1365-246X.2005.02569.x

Sammis, C. G., \& Rice, J. R. (2001). Repeating earthquakes as low-stress-drop events at a border between locked and creeping fault patches. Bulletin of the Seismological Society of America, 91(3), 532-537. https://doi.org/10.1785/0120000075

Schaff, D. P., Beroza, G. C., \& Shaw, B. E. (1998). Postseismic response of repeating aftershocks. Geophysical Research Letters, 25(24), 4549-4552. https://doi.org/10.1029/1998GL900192

Schmittbuhl, J., Karabulut, H., Lengliné, O., \& Bouchon, M. (2016). Long-lasting seismic repeaters in the Central Basin of the Main Marmara Fault. Geophysical Research Letters, 43, 9527-9534. https://doi.org/10.1002/2016GL070505

Scholz, C., Dawers, N., Yu, J.-Z., Anders, M., \& Cowie, P. (1993). Fault growth and fault scaling laws: Preliminary results. Journal of Geophysical Research, 98(B12), 21,951-21,961. https://doi.org/10.1029/93JB01008

Shearer, P. M., Prieto, GermánA, \& Hauksson, E. (2006). Comprehensive analysis of earthquake source spectra in Southern California. Journal of Geophysical Research, 111, B06303. https://doi.org/10.1029/2005JB003979

Templeton, D. C., Nadeau, R. M., \& Bürgmann, R. (2008). Behavior of repeating earthquake sequences in central California and the implications for subsurface fault creep. Bulletin of the Seismological Society of America, 98(1), 52-65. https://doi.org/10.1785/0120070026

Torabi, A., \& Berg, S. S. (2011). Scaling of fault attributes: A review. Marine and Petroleum Geology, 28(8), 1444-1460. https://doi.org/10. 1016/j.marpetgeo.2011.04.003

Uchida, N., Asano, Y., \& Hasegawa, A. (2016). Acceleration of regional plate subduction beneath Kanto, Japan, after the 2011 Tohoku-oki earthquake. Geophysical Research Letters, 43, 9002-9008. https://doi.org/10.1002/2016GL070298

Uchida, N., \& Bürgmann, R. (2019). Repeating earthquakes. Annual Review of Earth and Planetary Sciences, 47, 305-332. https://doi.org/ 10.1146/annurev-earth-053018-060119

Waldhauser, F. (2009). Near-real-time double-difference event location using long-term seismic archives, with application to Northern California. Bulletin of the Seismological Society of America, 99(5), 2736-2748. https://doi.org/10.1785/0120080294

Waldhauser, F., Ellsworth, W., Schaff, D. P., \& Cole, A. (2004). Streaks, multiplets, and holes: High-resolution spatio-temporal behavior of Parkfield seismicity. Geophysical Research Letters, 31, L18608. https://doi.org/10.1029/2004GL020649

Waldhauser, F., \& Schaff, D. P. (2008). Large-scale relocation of two decades of Northern California seismicity using cross-correlation and double-difference methods. Journal of Geophysical Research, 113, B08311. https://doi.org/10.1029/2007JB005479

Walsh, J. J., \& Watterson, J. (1988). Analysis of the relationship between displacements and dimensions of faults. Journal of Structural Geology, 10(3), 239-247. https://doi.org/10.1016/0191-8141(88)90057-0

Watterson, J. (1986). Fault dimensions, displacements and growth. Pure and Applied Geophysics, 124(1-2), 365-373. https://doi.org/10. 1007/BF00875732

Wyss, M., Sammis, C. G., Nadeau, R. M., \& Wiemer, S. (2004). Fractal dimension and $b$-value on creeping and locked patches of the San Andreas fault near Parkfield, C. Bulletin of the Seismological Society of America, 94(2), 410-421.

Yamashita, Y., Shimizu, H., \& Goto, K. (2012). Small repeating earthquake activity, interplate quasi-static slip, and interplate coupling in the Hyuga-nada, southwestern Japan subduction zone. Geophysical Research Letters, 39, L08304. https://doi.org/10.1029/2012GL051476 
Ye, L., Lay, T., Koper, K. D., Smalley, R. Jr., Rivera, L., Bevis, M. G., et al. (2014). Complementary slip distributions of the August 4, 2003 $M_{w} 7.6$ and November 17, $2013 M_{w} 7.8$ South Scotia Ridge earthquakes. Earth and Planetary Science Letters, 401, 215-226. https://doi. org/10.1016/j.epsl.2014.06.007

Yu, W.-C. (2013). Shallow-focus repeating earthquakes in the Tonga-Kermadec-Vanuatu subduction zones. Bulletin of the Seismological Society of America, 103(1), 463-486. https://doi.org/10.1785/0120120123

Zhang, J., Richards, P. G., \& Schaff, D. P. (2008). Wide-scale detection of earthquake waveform doublets and further evidence for inner core superrotation. Geophysical Journal International, 174(3), 993-1006. https://doi.org/10.1111/j.1365-246X.2008.03856.X

\section{References From the Supporting Information}

Freedman, D., \& Diaconis, P. (1981). On the histogram as a density estimator: L 2 theory. Zeitschrift für Wahrscheinlichkeitstheorie und verwandte Gebiete, 57(4), 453-476. https://doi.org/10.1007/BF01025868 